\title{
Chikungunya antibodies detected in non-human primates and rats in three Indian Ocean islands after the 2006 ChikV outbreak
}

\author{
Gwenaël Vourc'h ${ }^{1 *}$, Lénaïg Halos ${ }^{1,6}$, Amélie Desvars $^{1,7}$, Franck Boué $^{2}$, Michel Pascal ${ }^{3^{\wedge}}$, Sylvie Lecollinet ${ }^{4}$, \\ Stéphan Zientara ${ }^{4}$, Thomas Duval ${ }^{5,8}$, Angella Nzonza ${ }^{4,5}$ and Michel Brémont ${ }^{5}$ \\ ${ }^{\wedge}$ This paper is dedicated to the memory of Michel Pascal deceased on 5 January 2013.
}

\begin{abstract}
The role of terrestrial vertebrates in the epidemiology of chikungunya disease is poorly understood. We evaluated their exposure and amplification role during the 2006 chikungunya outbreak in the Indian Ocean. Blood samples were collected from 18 mammalian and reptile species from Reunion Island, Mauritius and Mayotte. Among the 1051 samples serologically tested for chikungunya virus (CHIKV), two crab-eating macaques (Macaca fascicularis) and two ship rats (Rattus rattus) proved to be exposed to CHIKV. CHIKV RNA was not detected in 791 analyzed sera. Our results confirm the preferential infection of simian primates and suggest that other vertebrates played a poor or no role in CHIKV transmission during the 2006 outbreak.
\end{abstract}

\section{Introduction, methods and results}

Since its first description in Tanzania in 1953, chikungunya virus (CHIKV) has caused numerous outbreaks in Africa and Southeast Asia. Since 2004, the incidence and geographical distribution of CHIKV have increased dramatically, with major epidemics reported on the Indian Ocean islands, in Asia, as well as in Africa. Furthermore, autochthonous outbreaks were reported in Italy (2007) and in France (2010) [1]. CHIKV is an arbovirus belonging to the Togaviridae family in the genus Alphavirus. As an arbovirus, CHIKV is of animal origin and originates from forest non-human primates (NHP) [2]. In Africa, the virus is maintained in a sylvatic cycle involving forest dwelling Aedes spp. mosquitoes and wild NHP, while in Asia CHIKV seems to have a primarily human-mosquito transmission cycle which periodically causes epidemics in urban centres involving $A$. aegypti as the main vector [1]. Sylvatic transmission has not been documented in Asia, although wild NHP have been found seropositive in Malaysia and in the Philippines [3,4].

\footnotetext{
*Correspondence: gvourch@clermont.inra.fr

Deceased

'Institut National de la Recherche Agronomique (INRA), UR346 Epidémiologie Animale, Saint-Genès-Champanelle, France

Full list of author information is available at the end of the article
}

Evidence that species other than NHP could be reservoir hosts for CHIKV and their potential roles in the virus epidemiology remains unclear. In Africa, some studies reported the presence of CHIKV antibodies in rodents, birds, and reptiles, as well as in domestic mammals living in close proximity to anthropophilic mosquito habitats $[5,6]$. However, the serological screenings were mainly based on haemagglutination-inhibition or complement fixation tests and were rarely confirmed by the virus neutralization test which is the reference method for CHIKV antibody detection. Few virus isolations have been reported from other species than NHP, including striped ground squirrels (Xerus erythropus), yellow bats (Scotophilus sp.), golden sparrows (Auripasser luteus) and Mus musculus mice [7].

Reunion Island (Indian Ocean) underwent an unforeseen outbreak of chikungunya disease, characterized by high fever and arthralgia, during the 2005-2006 austral summer. Approximately 266000 people out of a total of 785 000 inhabitants [8] suffered from infection between April 2005 and July 2006. The virus that reached Reunion Island in 2005 belonged to the East-Central-South-African and Indian Ocean group [9] and was a new variant efficiently transmitted by A albopictus [10]. With the exception of humans and a couple of specimens in zoological gardens, Reunion Island does not host NHP whereas Mayotte and 
Mauritius count an important population of Eulemur fulvus (brown lemurs) and Macaca fascicularis (crabeating macaques) respectively. Since A. albopictus can feed on various vertebrates in Asia and recently invaded locations including Reunion Island [11,12], vertebrates from Reunion Island may have been exposed to CHIKV during the epidemics.

The aim of our study was to investigate the presence of CHIKV in terrestrial vertebrates to study the role that they may have played in the 2006 chikungunya epidemic on the Indian Ocean islands. We sampled 1172 specimens belonging to 18 wild and domestic non-primate vertebrate species from La Reunion, Mayotte and Mauritius (see Figure 1 and Table 1). Domestic species (dogs and cats) suspected to be at risk of CHIKV infection were sampled, namely symptomatic animals with arthralgia, myalgia and fever or animals belonging to patients recently diagnosed with chikungunya disease. Moreover, NHP from Reunion Island zoological garden, wild lemurs from Mayotte, and macaques from Mauritius were also sampled. Whenever possible, 40 individuals per species were trapped according to a recommended procedure. Blood samples were collected at classic puncture sites and sera were extracted after centrifugation. Kidney, spleen, and liver were sampled on euthanized rats, mice and shrews and stored at $-80{ }^{\circ} \mathrm{C}$ for virus detection. This study was performed in strict accordance with the French guidelines on animal experimentation and welfare.

CHIKV antibodies were identified by indirect ELISA, by virus neutralization, and by indirect immunofluorescence assays (using the CHIKV isolate 695, isolated on Reunion
Island in 2005 and kindly provided by I. Leparc-Goffart, IRBA, Marseille, France). ELISA plates were coated with UV-inactivated CHIKV ( $10^{6}$ particles per well) or CHIKV cell-culture antigens provided by Institut Pasteur Lyon, France (250 ng/well); diluted serum samples (1/100) were added after completion of the blocking step and appropriate HRP-conjugated secondary antibodies (Jackson ImmunoResearch Europe Ltd, Suffolk, UK, with dilutions ranging from $1 / 1000$ for most species to $1 / 100000$ for anti-cat IgG) were used. A positive control, consisting of a human positive serum (Institut Pasteur Lyon, France) was added in each ELISA plate and the ELISA cut-off was determined as the mean optical density of negative sera plus $2 \mathrm{SD}$. The presence of anti-CHIKV antibodies was monitored in 12 sera (7 ELISA positive and 5 ELISA negative) by indirect immunofluorescence assay (IFA) on Vero cells $48 \mathrm{~h}$ postinfection with $0.1 \mathrm{MOI}$ of CHIKV. Cells were fixed and incubated with serially diluted sera before addition of fluorescein isothiocyanate-conjugates (anti-rat conjugate for ship rats, anti-monkey conjugate for lemurs and macaques, $\operatorname{IgG}(\mathrm{H}+\mathrm{L})$, Paris, Compiègne, France) diluted 1/ 100 in PBS-Tween 20 0.05\%. Fluorescence was monitored at magnification 40X (Zeiss microscope). Moreover, a 96well microneutralization test was used to confirm the results obtained in ELISA for 10 sera. A serum was considered positive if Vero cells were protected at the 1/20 dilution. Sera and organs (liver, kidney and spleen) from the 3 ELISA-positive rats were also tested for the presence of CHIKV RNA. Ten $\mu \mathrm{L}$ of enterovirus nucleic acid were added to $100 \mu \mathrm{L}$ of each serum to control the extraction process. RNA of the resulting solution was extracted

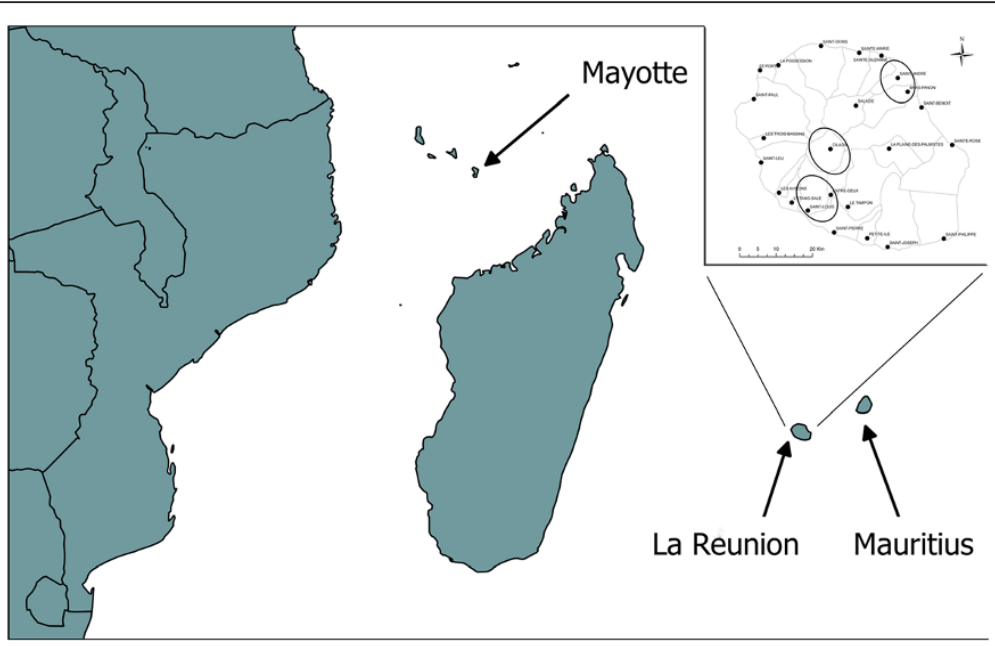

Figure 1 Map of the Indian Ocean with the $\mathbf{3}$ study areas, Mayotte, Mauritius and Reunion Islands. In total, 54 brown lemurs from Mayotte, 134 crab-eating macaques from Mauritius and 984 animals belonging to 17 species from Reunion were sampled. On Reunion (upper right corner), the 3 main sampling zones were located in the district of Saint-André (east, 322 individuals), the district of Saint-Louis (south-west, 308 individuals) and the Cirque of Cilaos (239 individuals). Ninety-four individuals originated from other areas, while 21 individuals were selected on account of an increased risk for CHIKV infection. 
Table 1 Number of specimens tested by qRT-PCR and by ELISA, and number of seropositive animals

\begin{tabular}{|c|c|c|c|c|}
\hline \multirow[b]{2}{*}{ Species } & \multirow[b]{2}{*}{ Sampling location } & \multirow{2}{*}{$\begin{array}{c}\text { qRT-PCR } \\
\text { Number tested* }\end{array}$} & \multicolumn{2}{|c|}{ ELISA } \\
\hline & & & Number tested & Number positive (\%) \\
\hline \multicolumn{5}{|l|}{ Domestic carnivores } \\
\hline Cat - Felis catus & Reunion & 38 & 37 & 0 \\
\hline Dog - Canis lupus & Reunion & 69 & 68 & 0 \\
\hline \multicolumn{5}{|l|}{ Farm mammals and poultry (Reunion Island) } \\
\hline Horse - Equus ferus & Reunion & 76 & 97 & 0 \\
\hline Cattle - Bos primigenius & Reunion & 115 & 116 & 0 \\
\hline Goat - Capra aegagrus & Reunion & 95 & 115 & 0 \\
\hline Sheep - Ovis aries & Reunion & 25 & 49 & 0 \\
\hline Pig - Sus scrofa & Reunion & 48 & 108 & 0 \\
\hline Poultry - Gallus gallus & Reunion & 37 & 113 & 0 \\
\hline \multicolumn{5}{|l|}{ Wild mammals } \\
\hline Shrew - Suncus murinus & Reunion & 105 & 45 & 0 \\
\hline Ship rat - Rattus rattus & Reunion & 74 & 75 & $3(4.0 \%)$ \\
\hline Norway rat - Rattus norvegicus & Reunion & 6 & 17 & 0 \\
\hline House mouse - Mus musculus & Reunion & 33 & 20 & 0 \\
\hline \multicolumn{5}{|l|}{ Reptiles } \\
\hline Panther chameleon - Chamaeleo pardalis & Reunion & 17 & not tested & not tested \\
\hline \multicolumn{5}{|l|}{ Non-human primates } \\
\hline Brown lemur - Eulemur fulvus & Mayotte & 53 & 52 & $2(3.8 \%)$ \\
\hline Crab-eating macaques - Macaca fascicularis & Mauritius & not tested & 134 & $1(0.7 \%)$ \\
\hline Crab-eating macaques - Macaca fascicularis & Reunion & not tested & 1 & $1(100.0 \%)$ \\
\hline Hamadryas Baboon - Papio hamadryas & Reunion & not tested & 2 & 0 \\
\hline Southern Pig-tailed Macaque - Macaca nemestrina & Reunion & not tested & 1 & 0 \\
\hline Campbell's Monkey - Cercopithecus campbelli & Reunion & not tested & 1 & 0 \\
\hline Total & & 791 & 1051 & 7 \\
\hline
\end{tabular}

${ }^{*}$ All samples were negative by qRT-PCR.

using Nucleospin II RNA Macherey Nagel kit (Düren, Germany). Extracts were then analyzed by qRT-PCR with $\mathrm{TaqMan}^{\circ}$ probes following a previously published protocol [13].

A total of 1172 animals were sampled between May 2006 and April 2007, among which 984 individuals belonging to 17 vertebrate species originating from Reunion Island, 54 brown lemurs from Mayotte and 134 crabeating macaques from Mauritius (see Table 1). Reunion Island samples included 21 domestic animals (17 dogs, two cats and two chickens) considered at risk for CHIKV infection.

Amongst the 1051 individuals analyzed by ELISA, seven were found positive: three of the 75 ship rats $(4.0 \%)$ tested from Reunion Island, two of the 52 brown lemurs from Mayotte (3.8\%), one of the 134 crab-eating macaques from Mauritius (0.7\%), and the one crab-eating macaque that was sampled at the Reunion Island zoo (see Table 1). The three seropositive rats were trapped in the east part near Saint-André on Reunion Island, an area where the prevalence of human infection was high. The presence of anti-CHIKV antibodies was confirmed by IFA and virus neutralization test in all the ELISA-positive crab-eating macaques and in two out of three ship rats, but could not be confirmed with the two ELISA-positive brown lemurs. Seven hundred ninety-one sera as well as organs (liver, kidney and spleen) from the seropositive rats were tested by qRT-PCR. All samples were RT-PCR negative (Table 1 ).

\section{Discussion}

Our investigation of the presence of CHIKV in domestic and wild vertebrates from three Indian Ocean islands, which underwent a huge CHIKV outbreak in humans in 2005-2006, revealed that terrestrial vertebrates were unfrequently exposed to CHIKV despite the high infection rate in the human population. Exposure to CHIKV was evidenced in all NHP species, including lemurs, present on the three considered islands and only three ship rats were tested seropositive out of the 979 non-primate vertebrates sampled. CHIKV RNA was not detected in any of 
the analyzed sera nor in the organs of the rats testing positive. These results confirmed the preferential association of CHIKV with humans and NHP and indicate that vertebrates other than NHP and ship rats are mainly dead-end hosts for CHIKV on Reunion Island. During the 2006 epidemic in the Indian Ocean, the virus seems to have circulated among a human-mosquito cycle in a similar manner to that found in Asia [14].

Seroprevalence against CHIKV among NHP was low on Reunion, Mayotte and Mauritius. Previously crab-eating macaques had been found seropositive in Malaysia using hemagglutination-inhibiting tests [4] and in the Philippines using ELISA tests [3]. Only ten crab-eating macaques were present in the zoo of Reunion Island when this work was conducted, thus the probability that this species had an epidemiological role in virus transmission on this island is negligible. In contrast, they may have played a role on Mauritius which counts thousands of macaques [15].

To our knowledge, the present study is the first to report the presence of CHIKV antibodies in lemurs and this finding should be considered with caution. Antibodies could be evidenced by indirect ELISA only, which suggests either that ELISA is more sensitive than the IFA or virus neutralization test, as generally reported in the literature [16] or that ELISA generated false positive results with sera of lemurs. Consequently, more data should be generated to confirm potential CHIKV infections in lemurs.

Marchette et al. described for the first time CHIKV infection in rodents, with low seropositive titres in one Rattus sabanus out of 353 trapped in Malaysia [4]. We failed to detect the CHIKV in the organs of the three seropositive Rattus rattus trapped on Reunion Island. These rats may have been in contact with the virus and carried the virus, but not long enough to detect it by qRT-PCR. Mayotte, Mauritius, and Reunion Island count a high number of introduced Rattus spp. which are able to adapt to a great variety of habitats, climates and tropic regimens, and are accordingly widespread (pers. obs.). Consequently, it would be interesting to test experimentally whether ship rats can amplify the virus and infect Aedes mosquitoes through blood meals, to further characterize the role of this species in the circulation and or dissemination of CHIKV in association with mosquitoes along commercial routes in the Indian Ocean.

The absence of antibodies in most vertebrates could be due $1 /$ to an absence of contact with CHIKV or 2/ to an absence of immune response induction following poor CHIKV replication. A study on Reunion Island indicates that although A. albopictus feeds preferentially on humans, this mosquito can feed on every domestic species that we tested in our study [11]. These data support our second hypothesis. Otherwise, several studies that relied mostly on haemagglutination inhibition tests have described CHIKV antibodies in the non-primate species that we sampled: poultry $[4,5]$, cattle $[4,17]$, sheep $[17,18]$, goats $[4,18]$, pigs $[4]$, horses $[4,19,20]$, and dogs [4]. No prior results are available for shrews, nor mice or chameleon, and one study reported negative results in cats [21]. These divergent results could result from specificity issues with the serological tools used or from differing CHIKV circulation patterns (with transmission cycles closer to the ones documented in Asia).

We did not detect any viremia in the sampled animals. Viremia in animals has been assessed only through experimental infections. These studies reported detectable viremia in NHP [22,23], rodents [24,25], but failed to detect CHIKV in other domestic species [22]. Upon CHIKV infection, viremia lasts a maximum of seven days after inoculation $[23,24]$. Due to the timing of the sampling campaign, which was initiated three months after the peak in human infections, viremia may have been missed [8].

In conclusion, the present study confirms the preferential association of CHIKV with simian NHP during the 2006 outbreak in the Indian Ocean region. It suggests that other vertebrates, including NHP did not play a role in the transmission during this outbreak.

\section{Competing interests}

The authors declare that they have no competing interests.

\section{Authors' contributions}

$\mathrm{GV}$ and $M B$ conceived and designed the experiments. $L H, A D, M P, T D$ took part in the sampling effort. GV, LH, AD, FB, SL, AN performed the analysis and interpreted the data. All authors contributed to the drafting and revision of the manuscript and have given their approval for publication of the latest version.

\section{Acknowledgments}

This project is most thankful to CIRAD Reunion for providing vital logistical support. We also offer our sincerest thanks to our partners for the sampling collection: on Reunion Island: GRDSBR, SEOR, veterinarians, DSV, LVD, DIREN, ONCFS/Brigade de la Nature de La Réunion, DRASS, the Zoo (JM Carenton and B Lefaux); on Mayotte: ONCFS/Brigade Nature and M Sigaud; on Mauritius: Noveprim and Bioculture. We are very grateful to G Aumont for support, C Punelle and F Jan for the intense field work, to T Palama, M Leberre and A Bouder for laboratory analyses, to H Delatte (IRD), P Kazup (ESF), A Michault and his GHSR team and to every members of the "Cellule nationale de coordination de la recherche sur la maladie du chikungunya" for their advice and support. We thank G Farre for its technical assistance in ELISA tests, M Grandadam for his expertise in CHIKV serological tests and Institut Pasteur de Lyon and IRBA for providing CHIKV antigens and isolate. We are thankful to N Dorr, V Poux, and AS Martel for the database and data entry. Finally, we thank $G$ Delobel for verifying our written English. This work was funded by INRA and the Agence Nationale de la Recherche (SEST-2006 Chik-Ani program).

\section{Author details}

${ }^{1}$ Institut National de la Recherche Agronomique (INRA), UR346 Epidémiologie Animale, Saint-Genès-Champanelle, France. ${ }^{2}$ Agence Nationale de Sécurité Sanitaire (ANSES), Laboratoire de la rage et de la faune sauvage de Nancy, Malzéville, France. ${ }^{3}$ INRA, UMR 0985 Écologie et Santé des Écosystèmes, Rennes, France. ${ }^{4}$ ANSES, Laboratoire de Santé Animale, UMR 1161 Virologie, Maisons-Alfort, France. ${ }^{5}$ INRA, UR892 Virologie et Immunologie Moléculaires, Jouy-en-Josas, France. ${ }^{6}$ Present address: MERIAL, Parasiticides and Pets, Lyon, 
France. ${ }^{7}$ Present address: Department of Clinical Microbiology, Umeå University, 90185 Umeå, Sweden. ${ }^{8}$ Present address: Société Calédonienne d'Ornithologie, Antenne Nord, Galerie Goropverbe Poindimié, Nouvelle Calédonie.

Received: 22 July 2013 Accepted: 14 April 2014 Published: 1 May 2014

\section{References}

1. Weaver SC: Evolutionary influences in arboviral disease. Curr Top Microbiol Immunol 2006, 299:285-314.

2. Powers AM, Brault AC, Tesh RB, Weaver SC: Re-emergence of Chikungunya and O'nyong-nyong viruses: evidence for distinct geographical lineages and distant evolutionary relationships. J Gen Virol 2000, 81:471-479.

3. Inoue S, Morita K, Matias RR, Tuplano JV, Resuello RR, Candelario JR, Cruz DJ, Mapua CA, Hasebe F, Igarashi A, Natividad FF: Distribution of three arbovirus antibodies among monkeys (Macaca fascicularis) in the Philippines. J Med Primatol 2003, 32:89-94.

4. Marchette NJ, Rudnick A, Garcia R, MacVean DW: Alphaviruses in Peninsular Malaysia: I. Virus isolations and animal serology. Southeast Asian J Trop Med Public Health 1978, 9:317-329.

5. Cornet M, Robin Y, Taufflieb R, Camicas J: Données préliminaires sur l'enquête sérologique "chikungunya" au Sénégal. In 8ème Conférence Technique de l'Organisation de Coordination et de Coopération pour la Lutte contre les Grandes Endémies: 1968; Bamako, Mali. 1968:569-574.

6. McIntosh BM, Paterson HE, McGillivray G, Desousa J: Further studies on Chikungunya outbreak in southern Rhodesia in 1962. I. Mosquitoes, wild primates and birds in relation to epidemic. Ann Trop Med Parasitol 1964, 58:45-51.

7. Karabatsos N: International catalogue of arboviruses. $3^{\text {rd }}$ edition. ASTMH: San Antonio, Texas, USA; 1985.

8. Chikungunya dans I'Océan Indien, Point au 19 avril 2007. [http://www. invs.sante.fr/presse/2007/le_point_sur/chikungunya_190407/index.html]

9. Schuffenecker I, Iteman I, Michault A, Murri S, Frangeul L, Vaney M, Lavenir R, Pardigon N, Reynes J, Pettinelli F, Biscornet L, Diancourt L, Michel S, Duquerroy $S$, Guigon G, Frenkiel MP, Bréhin AC, Cubito N, Desprès $P$, Kunst F, Rey FA, Zeller H, Brisse S: Genome microevolution of Chikungunya viruses causing the Indian Ocean outbreak. PLoS Med 2006, 3:1-13.

10. Vazeille M, Moutailler S, Coudrier D, Rouseaux C, Khun H, Huerre M, Thiria J, Dehecq JD, Fontenille D, Schuffenecker I, Despres P, Failloux AB: Two Chikungunya isolates from the outbreak of La Reunion (Indian Ocean) exhibit different patterns of infection in the mosquito, Aedes albopictus. PLoS One 2007, 2:e1168.

11. Delatte H, Desvars A, Bouétard A, Bord S, Gimonneau G, Vourc'h G, Fontenille D: Blood-feeding behavior of Aedes albopictus, vector of Chikungunya on La Réunion. Vector Borne Zoonotic Dis 2010, 10:249-258.

12. Hawley WA: The biology of Aedes albopictus. J Am Mosq Control Assoc Suppl 1988, 1:1-39.

13. Pastorino B, Bessaud M, Grandadam M, Murri S, Tolou HJ, Peyrefitte CN: Development of a TaqMan ${ }^{\oplus}$ RT-PCR assay without RNA extraction step for the detection and quantification of African Chikungunya viruses. J Virol Methods 2005, 124:65-71.

14. Tollenaere C, Brouat C, Duplantier J-M, Rahalison L, Rahelinirina S, Pascal M, Moné H, Mouahid G, Leirs H, Cosson J-F: Phylogeography of the introduced species Rattus rattus in the western Indian Ocean, with special emphasis on the colonization history of Madagascar. J Biogeogr 2010, 37:398-410.

15. Sussman RW, Tattersall I: Distribution, abundance, and putative ecological strategy of Macaca fascicularis on the Island of Mauritius, southwestern Indian Ocean. Folia Parasitol 1986, 46:28-43.

16. Coates DM, Makh SR, Jones N, Lloyd G: Assessment of assays for the serodiagnosis of Venezuelan equine encephalitis. J Infect 1992, 25:279-289.

17. Dickinson DB, McGillivray GM, McIntosh BM, Winter P: Antibodies against certain arboviruses in sera from human beings and domestic animals from the south-western and north-western regions of the Cape Province of South Africa. S Afr J Med Sci 1965, 30:11-18

18. Adesina OA, Odelola HA: Ecological distribution of Chikungunya haemagglutination inhibition antibodies in human and domestic animals in Nigeria. Trop Geogr Med 1991, 43:271-275.
19. Olaleye OD, Oladosu LA, Omilabu SA, Baba SS, Fagbami AH: Complement fixing antibodies against arboviruses in horses at Lagos, Nigeria. Rev Elev Med Vet Pays Trop 1989, 42:321-325.

20. Widjadja S, Soekotjo W, Hartati S, Jenning JB, Corwin AL: Prevalence of hemagglutination-inhibition and neutralizing antibodies to arboviruses in horses in Java. Southeast Asian J Trop Med Public Health 1995, 26:109-113.

21. Halstead SB, Udomsakdi S: Vertebrate hosts of Chikungunya virus. Bulle World Health Organ 1966, 35:89.

22. McIntosh BM, Paterson HE, Donaldson JM, De Sousa J: Chikungunya virus: viral susceptibility and transmission studies with some vertebrates and mosquitoes. S Afr J Med Sci 1963, 28:45-52.

23. Paul SD, Singh KR: Experimental infection of Macaca radiata with Chikungunya virus and transmission of virus by mosquitoes. Indian J Med Res 1968, 56:802-811.

24. McIntosh BM: Susceptibility of some African wild rodents to infection with various arthropod-borne viruses. Trans R Soc Trop Med Hyg 1961, 55:63-68.

25. Chakravarty SK, Sarkar JK: Susceptibility of new born and adult laboratory animals to Chikungunya virus. Indian J Med Res 1969, 57:1157-1164.

doi:10.1186/1297-9716-45-52

Cite this article as: Vourc'h et al:: Chikungunya antibodies detected in non-human primates and rats in three Indian Ocean islands after the 2006 ChikV outbreak. Veterinary Research 2014 45:52.

\section{Submit your next manuscript to BioMed Central and take full advantage of:}

- Convenient online submission

- Thorough peer review

- No space constraints or color figure charges

- Immediate publication on acceptance

- Inclusion in PubMed, CAS, Scopus and Google Scholar

- Research which is freely available for redistribution
Ciomed Central 